\title{
Late mortality after vagotomy and drainage for duodenal ulcer
}

\author{
P C H WATT, C C PATTERSON，T L KENNEDY
}

\begin{abstract}
Seven hundred and thirty five patients who underwent elective vagotomy and drainage procedures in one hospital during 1957-67 were followed up until 1 September 1982. At this time 281 were dead compared with an expected 184. This gives a ratio of observed to expected deaths of $1.53(p<0.0001)$. The most important cause of increased mortality was lung cancer, which accounted for 33 of the excess deaths (observed to expected ratio 3.53 ). Gastric cancer yielded an observed to expected ratio of $3 \cdot 3$. Other causes of death that were significantly more common than expected were cerebrovascular accident, bronchopneumonia, and colorectal cancer.

It is concluded that although gastric cancer occurs more commonly after vagotomy and drainage than in the general population, it is not as important a cause of death as diseases related to smoking.
\end{abstract}

\section{Introduction}

There is general agreement that patients who have undergone surgery for benign ulcer have a reduced long term survival. This view is based on two studies that dealt mainly with patients who had undergone gastrectomy. ${ }^{2}$ In 1982 McClean Ross et al investigated the long term survival of men who had undergone surgery for peptic ulcer between 1947 and 1965; most of their patients had also undergone gastrectomy, with only $13 \%$ having undergone vagotomy and drainage. ${ }^{3}$

A large proportion of patients currently alive after gastric surgery have undergone vagotomy and drainage, and thus it is

Queen's University of Belfast, Belfast

P C H WATT, MB, FRCS, senior house officer, department of pathology

C C PATTERSON, MSC, lecturer, department of medical statistics

Royal Victoria Hospital, Belfast

T L KENNEDY, MS, FRCS, consultant surgeon

Correspondence to: Mr P C H Watt, Institute of Pathology, Royal Victoria Hospital, Belfast BT12 6BJ, Northern Ireland. important to know whether they also have a reduced life expectancy. Knowledge of the cause of death in these patients is also important so that various diseases can be specifically looked for at follow up clinics. The cause of the increased mortality, particularly that due to gastric carcinoma, among patients after gastrectomy is the subject of conflicting evidence. Krause found that more of his patients had died from gastric carcinoma than expected, ${ }^{1}$ whereas $\mathrm{McClean}$ Ross et al and Liavaag found no such excess. ${ }^{3}{ }^{4}$ Unlike patients after gastrectomy, patients who have undergone vagotomy and drainage retain the gastric antrum, which is the commonest site of gastric cancer; thus they may possibly be more prone to this condition.

\section{Patients and methods}

The theatre records of the Royal Victoria Hospital, Belfast, for 1957 to 1967 inclusive were searched for all patients who had undergone elective vagotomy and gastrojejunostomy or vagotomy and pyloroplasty for duodenal ulcer who were born after 1900. Both truncal and selective vagotomies were included. Patients' addresses were found from hospital records or the hospital admissions book. With knowledge of the patients' names, dates of birth, and addresses at the time of operation the Northern Ireland Central Services Agency was able to supply the name of each patient's current general practitioner for those still alive. General practitioners were telephoned to confirm that the patients were alive. When the agency did not have any records of particular patients a search was made in the Northern Ireland register of deaths, and when death certificates were found the date and certified causes of death were recorded. When patients were still unaccounted for attempts were made to trace them from street directories, the electoral register, and pension records. Patients were accepted as being alive if they were contacted direct by telephone or letter, or if a close neighbour or relative was able to state categorically that they were alive. If relatives or neighbours stated that a patient was dead, the death certificate was traced in the Northern Ireland, Scottish, or English registers of deaths. Attempts were also made to trace patients who had emigrated.

For the purposes of statistical analysis it was necessary to compare the observed number of deaths with the expected number of deaths, taking into account the sex and age distributions of the patients and the calendar years during which follow up occurred. The method used for calculating expected numbers of deaths was based on person years at risk. The follow up interval was split into five periods each of five years, beginning in 1958. Seven age groups were used, each 
of 10 years, starting at age 15 . The Northern Ireland Registrar General's annual reports were used to obtain pooled death rates for each age group in each of the five periods. Rates for the final period, 1978-82, were estimated from figures from the reports for 1978-80 (the latest available). All rates were calculated for each sex separately. For each patient the years at risk in each age group and in each period were calculated. These figures were then cumulated over all patients to give the total person years at risk for each age group/sex/calendar period. Multiplication by the death rate for the corresponding age group/sex/calendar period gave the expected number of deaths.

The process described above was repeated for 15 distinct causes of death. These causes were selected so that compatibility was maintained across the three revisions of the International Classification of Diseases used by the Registrar General in the study period (revision 7 in 1958-67, revision 8 in 1968-78, and revision 9 in 1979-80).

Tests of significance for comparing observed and expected numbers of deaths were based on the Poisson distribution. Life tables and survival curves were constructed using the actuarial method.

\section{Results}

Seven hundred and thirty seven patients had elective vagotomy and drainage during the period of study. Patients who had emergency operations were excluded. Two who died within one month after operation were excluded on the basis of postoperative death. Of the 735 remaining, $576(78.4 \%)$ were men and $159(21.6 \%)$ women. On 1 September 1982, 24 patients were unaccounted for, though many had been followed up for part of the period; thus $711(96 \cdot 7 \%)$ were fully followed up, of whom $281(39.5 \%)$ died. The expected number of deaths in the group was $184 \cdot 1$, giving a ratio of observed to expected deaths of $1.53(\mathrm{p}<0.0001)$. This excess mortality applied to both men (224 observed compared with $157 \cdot 7$ expected deaths) and women ( 57 observed compared with 26.4 expected).

The survival curves for all 576 men and 159 women (fig 1) show the life table estimate of the proportion of the total surviving plotted against years from operation. Comparison with the expected survival curve indicates that there was an excess number of deaths among both men and women.

The considerably reduced survival was seen in all age groups coming to operation. Figure 2 shows observed and expected survival curves for patients aged 35-44, 45-54, and 55-64, respectively, at the time of operation. In those aged under 35 years the numbers dying were too small to yield reliable comparisons of observed with expected figures, and therefore survival curves for these ages are not given.
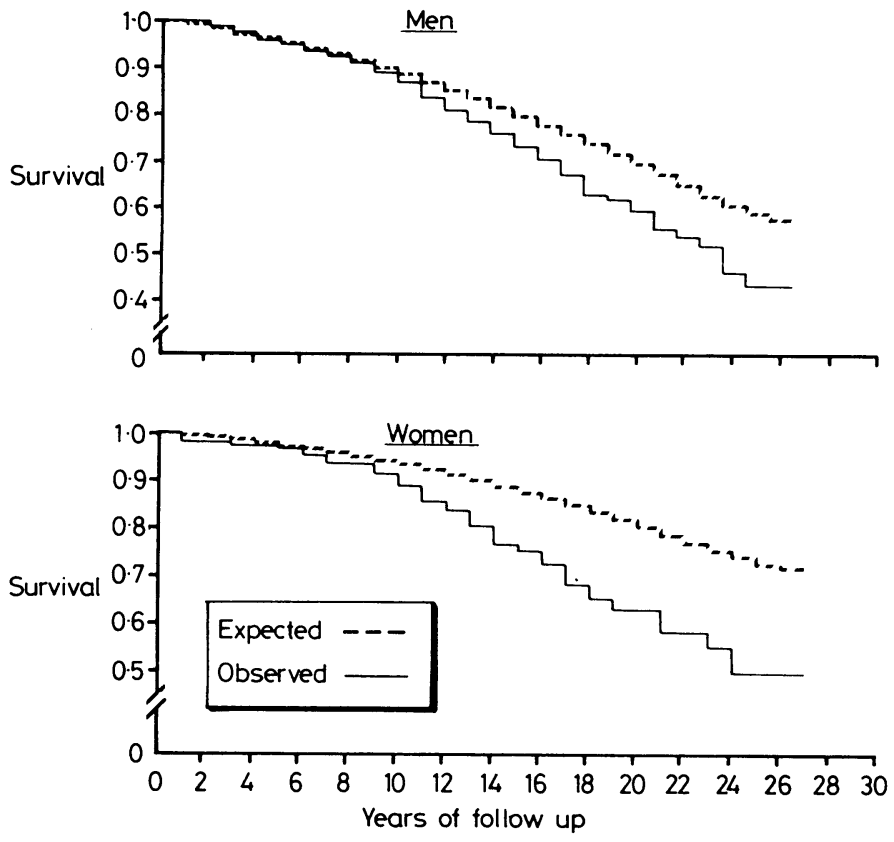

FIG 1-Survival curves for all men and women.
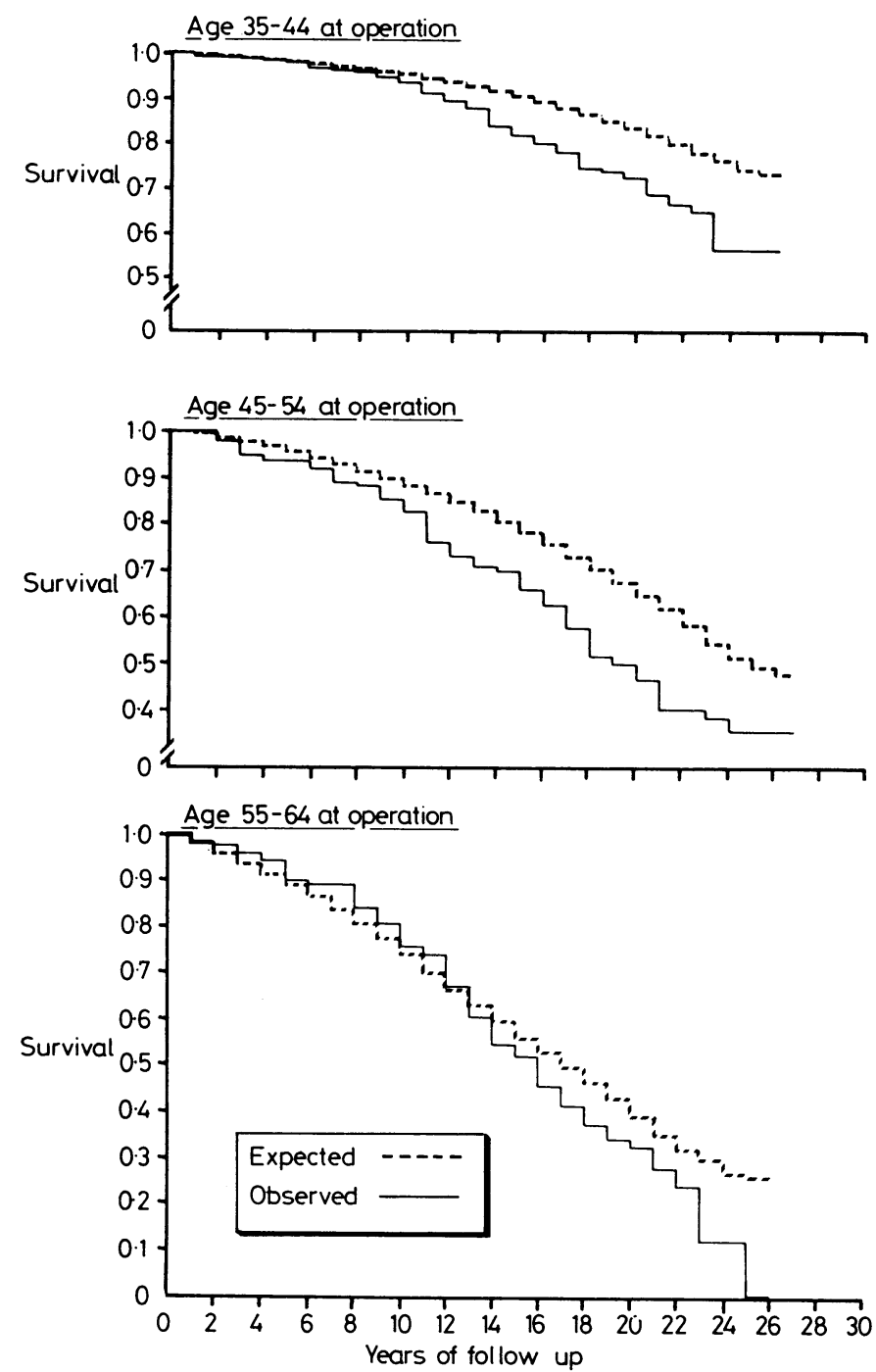

FIG 2-Survival curves for patients according to age at operation.

Table I gives the observed and expected numbers of deaths/1000 patients/year for each age and sex. The observed death rate is that for all the patients irrespective of when they underwent the operation or their age at operation. The excess number of deaths/1000/year increased with age at death.

Table II shows the numbers of deaths observed and expected broken down by cause. Significantly more deaths due to cerebrovascular accident, bronchopneumonia, lung cancer, colorectal cancer, and carcinoma of the stomach were observed than expected. Of the 16 patients who died of carcinoma of the stomach, 12 were men. Fourteen had undergone vagotomy and gastrojejunostomy and two vagotomy and pyloroplasty. The median interval between operation and death in these patients was 13 years (range 3-23 years).

\section{Discussion}

The figures quoted in this study, in common with those of several other studies, ${ }^{135}$ were derived from data on death certificates. Although this gives a good measure of overall mortality, the actual cause of death stated may not be totally accurate.$^{6}$ The major advantage of this type of study, however, is that the same method of recording death is applied to both the study group and the population. The incidence of various diseases found at necropsy in a group of patients after gastric surgery would be difficult to compare with the normal incidence as necropsy is not carried out on all people who die. Therefore, 
though we accept the shortcomings of death certificate data, we do not know any other feasible method of performing a valid retrospective comparison of causes of death between a study group and the population.

The overall ratio of observed to expected mortality found in this study of patients after vagotomy and drainage (1.53) is similar to that found in two studies of patients after gastrectomy $\left(1.4^{2}\right.$; and 1.55 in men and 1.15 in women $\left.{ }^{7}\right)$ but higher than that found in another study $(1 \cdot 3) .{ }^{1}$ This tends to confirm the prediction that the move from gastrectomy to more conservative operations would not be followed by an appreciable improvement in life expectancy in patients with peptic ulcer. ${ }^{3}$

The reduced survival occurred in both men and women and in all age groups considered. In general, survival curves are more reliable in the earlier years of follow up, before patient numbers have appreciably decreased.

As this and other studies ${ }^{13}$ compared mortality among patients after gastric surgery with that among the population we do not know whether the excess mortality is a result of the operation or the peptic ulcer disease. In a study of patients gastric surgery. Surprisingly, in the study by McClean Ross et $a l$, which investigated mainly patients after gastrectomy, ${ }^{3}$ and in our study there was no excess mortality due to ischaemic heart disease. McClean Ross et al suggested that this was partly because their patients were mainly operated on while in their 40s whereas the strongest link with smoking occurs in patients under 45. Doll and Peto, in an investigation of British doctors, found that the association between ischaemic heart disease and smoking is less strong than that between lung cancer and smoking and that the relation between ischaemic heart disease and smoking occurred most strongly in those aged under $45 .{ }^{9}$ Of our patients, $52 \%$ were aged under 45 at the time of operation, but only about one quarter of the person years of follow up occurred in patients before age 45. Interestingly, we observed a significant excess of deaths due to ischaemic heart disease in the under $45 \mathrm{~s}$ (21 observed compared with $12 \cdot 9$ expected).

The most striking difference between our study and the nearest comparable study in geographical and chronological terms on patients after gastrectomy ${ }^{3}$ is the excess mortality from

TABLE I-Observed and expected numbers of deaths by age in 735 patients who underwent surgery for duodenal ulcer during $1957-67$

\begin{tabular}{|c|c|c|c|c|c|c|c|c|}
\hline \multirow{3}{*}{ Age (years) } & \multicolumn{4}{|c|}{ Men } & \multicolumn{4}{|c|}{ Women } \\
\hline & \multirow{2}{*}{$\begin{array}{c}\text { Observed No of } \\
\text { deaths }\end{array}$} & \multirow{2}{*}{$\begin{array}{l}\text { Person years } \\
\text { of follow up }\end{array}$} & \multicolumn{2}{|c|}{ No of deaths $/ 1000 /$ year } & \multirow{2}{*}{$\begin{array}{c}\text { Observed No of } \\
\text { deaths }\end{array}$} & \multirow{2}{*}{$\begin{array}{l}\text { Person years } \\
\text { of follow up }\end{array}$} & \multicolumn{2}{|c|}{ No of deaths $/ 1000 /$ year } \\
\hline & & & Observed & Expected & & & Observed & Expected \\
\hline $\begin{array}{l}15-24 \\
25-34 \\
35-44 \\
45-54 \\
55-64 \\
65-74 \\
75-84\end{array}$ & $\begin{array}{r}0 \\
0 \\
7 \\
45 \\
78 \\
74 \\
20\end{array}$ & $\begin{array}{r}77 \\
475 \\
1864 \\
3060 \\
2598 \\
1076 \\
101\end{array}$ & $\begin{array}{r}0 \\
0 \\
4 \\
15 \\
30 \\
69 \\
199\end{array}$ & $\begin{array}{r}1 \\
1 \\
3 \\
8 \\
22 \\
54 \\
121\end{array}$ & $\begin{array}{r}0 \\
0 \\
2 \\
11 \\
32 \\
10 \\
2\end{array}$ & $\begin{array}{r}15 \\
91 \\
418 \\
942 \\
810 \\
281 \\
41\end{array}$ & $\begin{array}{r}0 \\
0 \\
5 \\
12 \\
39 \\
36 \\
49\end{array}$ & $\begin{array}{r}0 \\
1 \\
2 \\
5 \\
12 \\
30 \\
78\end{array}$ \\
\hline $15-84$ & 224 & $9252^{*}$ & 24 & 17 & 57 & 2598 & 22 & 10 \\
\hline
\end{tabular}

*This differs from the total number of person years of follow up by each age group because of rounding errors.

TABLE II-Observed and expected numbers of deaths by underlying cause in 735 patients who underwent surgery for duodenal ulcer during 1957-67

\begin{tabular}{|c|c|c|c|c|}
\hline & Observed & Expected & $\begin{array}{c}\text { Ratio of } \\
\text { observed:expected }\end{array}$ & Significance \\
\hline $\begin{array}{l}\text { Non-rheumatic heart } \\
\text { disease } \\
\text { Cerebrovascular accident } \\
\text { Chronic bronchitis } \\
\text { Bronchopneumonia } \\
\text { Suicide } \\
\text { Accident } \\
\text { Cirrhosis of liver } \\
\text { Peripheral vascular disease } \\
\text { Lung cancer } \\
\text { Carcinoma of oesophagus } \\
\text { Carcinoma of stomach } \\
\text { Carcinoma of pancreas } \\
\text { Carcinoma of rectum and } \\
\text { colon } \\
\text { Carcinoma of prostate } \\
\text { Carcinoma of breast } \\
\text { Other causes }\end{array}$ & $\begin{array}{r}77 \\
29 \\
15 \\
17 \\
4 \\
8 \\
3 \\
1 \\
46 \\
3 \\
16 \\
4 \\
12 \\
12 \\
2 \\
4 \\
40\end{array}$ & $\begin{array}{r}73 \cdot 7 \\
18.5 \\
10 \cdot 7 \\
4 \cdot 4 \\
1 \cdot 2 \\
6 \cdot 2 \\
1.0 \\
3.0 \\
13 \cdot 0 \\
1.0 \\
4 \cdot 8 \\
2.0 \\
5 \cdot 2 \\
1.6 \\
1.7 \\
36 \cdot 0\end{array}$ & $\begin{array}{l}1.04 \\
1.57 \\
1.40 \\
3.8 \\
3.5 \\
1.3 \\
3.0 \\
0.3 \\
3.53 \\
3.0 \\
3.3 \\
2.0 \\
2.3 \\
1.2 \\
2.4 \\
1.11\end{array}$ & $\begin{array}{c}\text { NS } \\
\mathrm{p}<0.05 \\
\mathrm{NS} \\
\mathrm{p}<0.0001 \\
\text { NS } \\
\text { NS } \\
\text { NS } \\
\text { NS } \\
\mathrm{p}<0.0001 \\
\text { NS } \\
\mathrm{p}<0.0001 \\
\mathrm{NS} \\
\mathrm{p}<0.05 \\
\text { NS } \\
\text { NS } \\
\text { NS }\end{array}$ \\
\hline
\end{tabular}

with peptic ulcer Viskum found no difference between those who had undergone operation and those who had not. ${ }^{8}$ This plus the fact that diseases related to smoking contribute considerably to the excess mortality suggest that the underlying disease and its associated smoking pattern are the most important factors in survival of these patients.

The pattern of causes of death appears to have changed appreciably since the early study by Krause in 1955, ${ }^{1}$ which found excess mortality due to tuberculosis, stomach cancer, and suicide but not to diseases related to smoking. In later studies, though suicide seems to have been more common than expected, tuberculosis has been much less important and the role of stomach cancer is disputed. ${ }^{23}$ On the other hand, these later studies, and our own, agree in showing that conditions related to smoking, especially lung cancer, are now well established as the major cause of excess mortality in patients after gastric cancer that we found. The question of inaccuracy of death certificates again arises, but we find it difficult to accept that it could account for a ratio of observed to expected deaths of 3.3. A possible explanation is that as the distal stomach is retained after vagotomy and drainage there is more mucosa available in which carcinoma may develop. In addition, gastric carcinoma is well known to be commonest in the antrum. Clark et al recently found that there was no strong relation between gastric cancer and gastrectomy, ${ }^{10}$ but Burns et al suggested that gastric cancer may be more common after vagotomy and drainage than after gastrectomy. ${ }^{11}$ Welvaart and Warnsinck suggested that only patients who develop gastric carcinoma five or more years after operation should be regarded as having carcinoma after gastric surgery, to avoid the possibility of considering patients in whom cancer was missed at the original operation. ${ }^{12}$ One of our patients developed gastric cancer after three years, but even if this is excluded the difference between the numbers of observed and expected deaths from gastric cancer is still highly significant. Most of those who died of gastric cancer had undergone vagotomy and gastrojejunostomy rather than vagotomy and pyloroplasty, and this difference may be due to the greater reflux of bile that occurs after gastrojejunostomy.

Other studies have shown an increased incidence of gastric carcinoma among patients after gastrectomy followed up over prolonged periods. Kraus found a ratio of observed to expected deaths from gastric cancer of 2.2 in patients operated on previously for gastric or duodenal ulcer. ${ }^{1}$ Helsingen and Hillestad found a ratio of 3.0 in patients after gastrectomy for gastric ulcer but no significant ratio in patients after gastrectomy for duodenal ulcer. ${ }^{5}$ Using a different approach, Stalsberg and Taksdal in a necropsy study found an increased incidence of gastric surgery among patients with gastric cancer provided that gastric surgery had been carried out more than 15 years previously. ${ }^{13}$ There was no difference in this respect between 
patients operated on for gastric or duodenal ulcer. To put these various findings into perspective, however, gastric cancer accounted for only 11 of the 97 excess deaths in our study whereas lung cancer accounted for 33 .

Our study confirms a previously documented relation between gastric surgery and colorectal carcinoma. ${ }^{3}$ Smoking state may partly explain this association, at least for carcinoma of the rectum. ${ }^{9} \mathrm{~A}$ further possibility is that bile salt metabolites, which are formed in the stomach after operation, ${ }^{14}$ could have a promoting effect on colonic carcinoma. ${ }^{15}$ An abnormality of bile salt metabolism has been suggested as a cause of the increased incidence of colonic cancer after cholecystectomy. ${ }^{16}$

Unfortunately, smoking state was not fully recorded for all patients in our study either at the time of operation or subsequently, but we recently clinically reviewed 264 of the survivors. Of these, $75 \%$ had been smokers at the time of operation but only $45 \%$ were smokers at the time of review. Among those who died probably a similar proportion had been smokers at operation but fewer may have given up smoking afterwards, though this must remain speculative.

In conclusion, our study of long term survival of patients who had undergone vagotomy and drainage showed that they are subject to an increased mortality, at least as great as that in patients after gastrectomy. Although cancer of the stomach occurred in excess, lung cancer accounted for a larger proportion of the excess deaths. We suggest that when patients attend clinics for long term follow up after gastric surgery they should be carefully questioned and examined for smoking related diseases. Frequent chest radiography is advisable, but regular endoscopy in all patients after gastric surgery yields little benefit.

\section{References}

${ }^{1}$ Krause U. Late prognosis after partial gastrectomy for ulcer. Acta Chir Scand 1958;114:341-54.

${ }^{2}$ Din NA, Small WP. Death after partial gastrectomy-a long term study. Gut 1974;15:335.

${ }^{3}$ Ross AHMcC, Smith MA, Anderson JR, Small WP. Late mortality after surgery for peptic ulcer. $N$ Engl f Med $1982 ; 307: 519-22$.

+ Liavaag K. Cancer development in gastric stump after partial gastrectomy for peptic ulcer. Ann Surg 1962;155:103-6.

5 Helsingen N, Hillestad L. Cancer development in the gastric stump after partial gastrectomy for ulcer. Ann Surg 1956;143:173-9.

${ }^{6}$ Cameron HM, McGrogan E. A prospective study of 1152 hospital autopsies. I. Inaccuracies in death certificates. $\mathcal{F}$ Pathol 1981 ;133:273-83.

${ }^{7}$ Westlund K. Mortality of peptic ulcer patients. Acta Med Scand 1963; 174, suppl 1402:1-110.

${ }^{8}$ Viskum K. Longevity and causes of death of peptic ulcer patients. Dan Med Bull 1976;233:136-43.

${ }^{9}$ Doll R, Peto R. Mortality in relation to smoking: 20 years' observations on male British doctors. Br Med f 1976;ii:1525-36.

1" Clark CG, Ward MWN, McDonald AM, Tovey FI. The incidence of gastric stump cancer. World $\mathcal{F}$ Surg 1983;7:236-40.

${ }^{11}$ Burns HJG, Totten J, George WD. Gastric carcinoma following different types of duodenal ulcer surgery [Abstract]. Clin Oncol (in press).

12 Welvaart K, Warnsinck HM. The incidence of carcinoma of the gastric remnant. F Surg Oncol 1982;21:104-6.

13 Stalsberg H, Taksdal S. Stomach cancer following gastric surgery for benign conditions. Lancet $1971 ;$ ii:1175-9.

${ }^{14}$ Domellof L, Reddy BS, Weisburger JH. Microflora and deconjugation of bile acids in alkaline reflux after partial gastrectomy. $\mathrm{Am} \mathcal{F}$ Surg 1980;140:291-5.

${ }^{15}$ Reddy BS, Narasana J, Weisburger JH. Promoting effect of sodium deoxycholate in colon adenocarcinoma in germ free rats. $\mathcal{F}$ Natl Cancer Inst $1976 ; 56: 441-2$.

16 Turnbull PRG, Smith AH, Isbister WH. Cholecystectomy and cancer of the large bowel. Br F Surg 1981;68:551-3.

(Accepted 16 February 1984)

\begin{abstract}
Mammary skin thickening shown on the mammogram was measured in 220 patients with non-inflammatory breast cancer, and the mean skin oedema was derived by taking the mean of five measurements from separate sites on the breast (upper part, lower part, medial part, lateral part, and areola) after subtracting the corresponding figures from the opposite (normal) breast.

The prevalence of appreciable oedema (greater than $0.25 \mathrm{~mm}$ ) was $70 \%$ for tumours less than $1 \mathrm{~cm}$ and $100 \%$ for tumours more than $3 \mathrm{~cm}$ in diameter. This measure of oedema correlated positively and significantly with tumour size and lymph node status. In a minimum of 60 months' follow up patients developing recurrence had

Departments of Surgery, Diagnostic Radiology, Medical Computing and Statistics, and Pathology, Welsh National School of Medicine, Heath Park, Cardiff CF4 4XN

H S SHUKLA, MS, FRCS, senior lecturer in surgery

I H GRAVELLE, FRCPED, FRCR, consultant radiologist

L E HUGHES, DS, FRCS, professor of surgery

$R$ G NEWCOMBE, PHD, lecturer in medical statistics

$S$ WILLIAMS, MB, BS, registrar
\end{abstract}

Correspondence to: Professor L E Hughes, University Department of Surgery. significantly higher oedema values. The amount of oedema also predicted recurrence better than lymph node status, tumour size, or tumour stage. Oedema and tumour size, information available preoperatively, provide a simple means of assessing prognosis before definitive treatment.

\section{Introduction}

Oedema of the mammary skin is well known to occur in the course of inflammatory carcinoma of the breast. Although it is often not visible to the naked eye, skin oedema is often present in non-inflammatory cancer and is clearly shown on xeromammograms. The clinical implications of skin oedema in non-inflammatory breast cancer have not been defined.

In the only study of skin oedema in non-inflammatory breast cancer we showed that the oedema could be measured accurately and reproducibly on xeromammograms and that it correlated significantly with other indices of the severity of the tumour such as clinical stage, size, lymph node status, and vascularity.' The amount of skin oedema also correlated well with prognosis over a follow up period of 7 to 70 months. This was not unexpected in view of the positive correlation of the amount of oedema with clinical and pathological prognostic indicators, but it was not clear whether this factor had an independent prognostic value, which could only be assessed over a longer period 